\title{
Comparison of Technetium-99m-MIBI imaging with MRI for detection of spine involvement in patients with multiple myeloma Siroos Mirzaei ${ }^{1}$, Martin Filipits ${ }^{4}$, Andrea Keck², Walter Bergmayer ${ }^{3}$, Peter Knoll1, Horst Koehn1, Heinz Ludwig² and Martin Pecherstorfer*2
}

\author{
Address: ${ }^{1}$ Ludwig Boltzmann Institute of Nuclear Medicine, Wilhelminenspital, Vienna, Austria, ${ }^{2} 1$ st Department of Medicine and Medical \\ Oncology, Wilhelminenspital, Vienna, Austria, ${ }^{3}$ Department of Radiology, Wilhelminenspital, Vienna, Austria and ${ }^{4}$ Division of Oncology, \\ Department of Internal Medicine I, University of Vienna, Vienna, Austria \\ Email: Siroos Mirzaei - siroos.mirzaei@wienkav.at; Martin Filipits - martin.filipits@akh-wien.ac.at; Andrea Keck - andrea.keck@wienkav.at; \\ Walter Bergmayer - walter.bergmayer@wienkav.at; Peter Knoll - peter.knoll@wienkav.at; Horst Koehn - horst.koehn@wienkav.at; \\ Heinz Ludwig - heinz.ludwig@wienkav.at; Martin Pecherstorfer* - Martin.Pecherstorfer@1me.wil.magwien.gv.at \\ * Corresponding author
}

Published: II December 2003

BMC Nuclear Medicine 2003, 3:2
Received: 27 October 2003

Accepted: II December 2003

This article is available from: http://www.biomedcentral.com//47I-2385/3/2

(C) 2003 Mirzaei et al; licensee BioMed Central Ltd. This is an Open Access article: verbatim copying and redistribution of this article are permitted in all media for any purpose, provided this notice is preserved along with the article's original URL.

\begin{abstract}
Background: Recently, radiopharmaceutical scanning with Tc-99m-MIBI was reported to depict areas with active bone disease in multiple myeloma (MM) with both high sensitivity and specificity. This observation was explained by the uptake of Tc-99m-MIBI by neoplastic cells. The present investigation evaluates whether Tc-99m-MIBI imaging and magnetic resonance imaging (MRI) perform equally well in detecting myelomatous bone marrow lesions.
\end{abstract}

Methods: In $2 \mathrm{I}$ patients with MM, MRIs of the vertebral region $\mathrm{TH} / 2$ to $\mathrm{SI}$ and whole body scans with Tc-99m-MIBI were done.

Results: Tc-99m-MIBI scanning missed bone marrow infiltration in 43 of 87 vertebrae $(50.5 \%)$ in which MRI showed neoplastic bone marrow involvement. In patients with disease stage I+II, Tc$99 \mathrm{~m}-$ MIBI scanning was negative in all of 24 vertebrae infiltrated according to MRI. In patients with disease stage III, Tc-99m-MIBI scanning detected 44 of 63 (70\%) vertebrae involved by neoplastic disease.

Conclusion: Tc-99m-MIBI scanning underestimated the extent of myelomatous bone marrow infiltration in the spine, especially in patients with low disease stage.

\section{Background}

The leading symptom of multiple myeloma (MM) is neoplastic bone involvement. Difficulties in diagnosing MM can arise from the fact that not all patients present with punched-out osteolytic lesions, the typical radiographic findings of MM. In $10-20 \%$ of patients with first diagnosis of $\mathrm{MM}$, the skeletal $\mathrm{x}$-rays are completely normal, and in up to $10 \%$ only osteoporosis-like changes can be detected. In contrast to skeletal radiography, which reveals the osseous destruction induced by myeloma cells, magnetic resonance imaging (MRI) directly depicts the initiator of bone lesions, myelomatous bone marrow infiltration [1]. Since bone marrow involvement can be visualized by MRI, even when the lytic lesions cannot be seen on skeletal radiographs, MRI has markedly improved the diagnosis and monitoring of MM [1]. Recently, radiopharmaceutical scanning with Technetium-99m 2 methoxy-isobutyl-isonitrile (Tc-99m-MIBI) was shown to 
demonstrate areas with active bone disease in $\mathrm{MM}$ with both high sensitivity and specificity [2-6]. Fonti et al. reported that myeloma cells directly take up Tc-99m-MIBI in vitro and that there is a close correlation between both the in vitro and in vivo uptake of the radiolabeled tracer and the bone marrow plasma cell infiltration shown by bone marrow aspiration [6]. Thus, Tc-99m-MIBI scanning reveals the presence of the infiltrating myeloma cells rather than its consequence, neoplastic bone destruction. However, in the studies published yet, the results of Tc99m-MIBI scanning have been correlated with plain skeletal radiographs and/or with bone scintigraphy, both examination methods which reveal the neoplastic bone destruction but not the bone marrow infiltration (as does $\mathrm{MRI}$ ). The aim of the present investigation was to evaluate whether MRI and Tc-99m-MIBI scanning perform equally well in detecting myelomatous bone marrow lesions in the spine as an often affected site.

\section{Patients and methods}

Twenty-one consecutive patients with MM (15 females, 6 males; median age 68 years, range: $39-88$ years) participated in the study. The diagnosis of MM and the staging of disease were based on standard criteria [7]. Four patients had disease stage I, 5 disease stage II and 12 disease stage III. Seventeen patients were entered into the study at first diagnosis of MM (prior to the first administration of chemotherapy or radiotherapy), 4 patients at disease progression. None of the patients had been irradiated in areas of the spine evaluated for myelomatous bone marrow infiltration by MRI or Tc-99m-MIBI scanning.

All patients underwent MRI of vertebrae TH12, L1, L2, L3, L4, L5 and S1. MRI was performed using a 1.0 Tesla Magneton Expert (Siemens) with a spinal coil. Sagittal images included a T1-weighted spin echo sequence and a fat-suppressed T2-weighted fast spin echo sequence. If a finding was ambiguous, the T1-weighted images were repeated after the intravenous injection of gadolinium chelate. All images were classified into two categories: normal findings and myelomatous involvement (focal, diffuse or heterogenous pattern) [1].

Anterior and posterior whole body scans ( 8 min for each projection) were obtained ten minutes, 1 hour, 4 hours and (in four randomly selected patients) 24 hours after the intravenous injection of $555 \mathrm{MBq}$ of Tc-99m-MIBI. A large field of view (LFOV) double head gamma camera (Elscint Helix; Haifa) equipped with a low-energy general purpose collimator was used. Additionally, one hour after tracer application, a posterior spot view of the lumbar vertebral column and pelvic area was performed using a lowenergy high resolution collimator. The scans were classified as showing [3]:
- a normal pattern with only physiological uptake (i.e., heart, liver and spleen),

- a pathologic pattern, with areas of focal tracer uptake and/or diffuse bone marrow uptake.

The two investigators (evaluating either the magnetic resonance images or the images obtained by Tc-99m-MIBI scanning) were blinded with regard to tumor stage and to the findings by the opposite imaging method.

If MRI or Tc-99m-MIBI scanning revealed several pathologic areas in one and the same vertebra of an individual patient, these were counted as one positive finding for the respective examination method.

Mononuclear cells isolated from bone marrow aspirates were available in 16 patients. These cells were stained with two different monoclonal antibodies that recognize different epitopes of the P-glycoprotein in order to evaluate the multi drug resistance as a possible reason for missing Tc-99m-MIBI uptake [8].

The study was performed in accordance with the Declaration of Helsinki, amended by the 29th (Tokyo) and 35th (Venice) World Medical Assembly, and in accordance with the pertinent national laws. The protocol was approved by the local ethical committees. Patients gave their informed consent prior to enrollment in the study.

\section{Results}

In the 21 patients, a total number of 147 vertebrae were examined. All the lesions found by Tc-99m-MIBI scanning were already detectable one hour after the administration of the radiolabelled tracer. The four-hour and 24-hour examinations did not further improve the results of the Tc-99m-MIBI scanning. In the entire collective, Tc-99mMIBI scanning missed myelomatous bone marrow infiltration in 43 of 87 vertebrae $(50.5 \%)$ in which MRI showed neoplastic bone marrow involvement (Table 1). In four patients, Tc-99m-MIBI scanning identified none of the vertebrae infiltrated according to MRI. Categorizing patients according to tumor stage revealed that in patients with disease stage I+II Tc-99m-MIBI scanning was negative in all of 24 vertebrae in which myelomatous infiltration was shown by MRI. In patients with disease stage III, Tc-99m-MIBI scanning detected 44 of 63 (70\%) involved vertebrae. Therefore, the proportion of involved vertebrae detected by Tc-99m-MIBI scanning was significantly (chisquare test: $p<0.002$ ) higher in patients with disease stage III than in patients with disease stage I+II. Tc-99mMIBI scanning was positive in only 4 vertebrae (of two patients with disease stage I) in which MRI showed a normal structure. In a follow-up of these 2 untreated patients 
Table I: Relationship of positive and negative findings in MRI and Tc-99m-MIBI scanning

\begin{tabular}{|c|c|c|c|c|c|c|c|}
\hline & \multicolumn{7}{|c|}{ Vertebral Body } \\
\hline & THI2 & LI & L2 & L3 & L4 & L5 & SI \\
\hline $\begin{array}{l}\text { MRI pos - MIBI } \\
\text { pos }\end{array}$ & 8 & 9 & 8 & 7 & 2 & 3 & 7 \\
\hline $\begin{array}{l}\text { MRI pos - MIBI } \\
\text { neg }\end{array}$ & 5 & 3 & 4 & 5 & 10 & 10 & 6 \\
\hline $\begin{array}{l}\text { MRI neg - MIBI } \\
\text { neg }\end{array}$ & 6 & 8 & 8 & 9 & 9 & 8 & 8 \\
\hline $\begin{array}{l}\text { MRI neg - MIBI } \\
\text { pos }\end{array}$ & 2 & I & 1 & 0 & 0 & 0 & 0 \\
\hline
\end{tabular}

two years later, examination by MRI still yielded no signs of neoplastic infiltration in these 4 vertebrae.

\section{Discussion and Conclusion}

In comparison with magnetic resonance imaging, Tc99m-MIBI scanning grossly underestimated the extent of myelomatous bone marrow infiltration, especially in patients with low disease stage. Since MM is a disease most often characterized by focal and not diffus neoplastic bone marrow infiltration, random bone marrow sampling may not be entirely diagnostic or predictive of disease status [7]. Thus, the observation of Fonti et al. who showed a significant correlation between the intensity of Tc-99m-MIBI uptake and plasma cell density in bone marrow aspirates should be considered with caution. In the majority of MM patients whose bone marrow is not diffusely infiltrated by neoplastic cells, MRI provides a better assessment of tumor load, than does single bone marrow aspiration [9]. However, the advantage of Tc-99m-MIBI scintigraphy is the image of whole body in one single examination and it is less time consuming than MRI and therefore more costeffective and comfortable for the patient.

According to Tirovola et al. [4], the false negative results of Tc-99m-MIBI scanning might be due to the presence of the multidrug resistance associated P-glycoprotein, which accelerates the efflux of Tc-99m-MIBI (and of several cytostatics) from MM cells. In our study, we tested for the presence of the P-glyocoprotein by means of immunocytochemistry. In the 16 patients examined (including three of the four patients with totally negative Tc-99m-MIBI scans but with lesions detected by MRI) no evidence of P-glycoprotein expression was found.

Further it must be taken into consideration, that a mild activity of $99 \mathrm{mTc}$ Tc-T9 $99 \mathrm{~m}-\mathrm{MIBI}$ can be observed even in normal bone and bone marrow [10]. Thus, further prospective studies with Tc-99m-MIBI seem to be necessary in order to define a reliable scintigraphic pattern, i.e. relative index to background or to an not affected skeletal area, for suspected parts of the skeleton as the spine, at which a site comparison is not possible as for the extremities.

\section{Competing interests}

None declared.

\section{Authors' contributions}

$\mathrm{MP}$ and HL designed the study and drafted the manuscript.

SM and HK carried out the nuclear medicine investigation.

PK was responsible for quality control of nuclear medicine investigation.

WM made the MRI analysis.

SM and AK performed the correlation of scintigraphic and MRI findings and participated in drafting the manuscript.

MF performed the immunochemistry examinations.

\section{Acknowledgements}

We thank Ms. Jane Neuda for editorial assistance.

The study was supported by a grant from "Oesterreichisches Forum gegen Krebs".

\section{References}

I. Moulopoulos LA, Varma DG, Dimopoulos MA, Leeds NE, Kim EE, Johnston DA, Alexanian R, Libshitz HI: Multiple myeloma: Spinal MR imaging in patients with untreated newly diagnosed disease. Radiology 1992, 185:833-840.

2. Durie BGM, Waxman A, Jochelson M, Giles FJ, Hamburg S, Avedon M: Technetium-99m-MIBI scanning in multiple myeloma. Proc Am Soc Clinl Oncol 1994, 13:4 I la.

3. Pace L, Catalano L, Pinto AM, De Renzo A, Di Gennaro F, Califano C, Del Vecchio S, Rotoli B, Salvatore M: Different patterns of technetium-99m sestamibi uptake in multiple myeloma. Europ J Nucl Med 1998, 25:714-720. 
4. Tirovola EB, Biassoni L, Britton KE, Kaleva N, Kouykin V, Malpas JS: The use of $99 \mathrm{mTC}$-MIBI scanning in multiple myeloma. $\mathrm{Br} J$ Cancer 1996, 74:1815-1820.

5. Alexandrakis MG, Kyriakou DS, Passam F, Koukouraki S, Karkavitsas $\mathrm{N}$ : Value of Tc-99m sestamibi scinitigraphy in the detection of bone lesions in multiple myeloma: comparison with Tc99m methylene diphosphonate. Ann Hematol 200I, 80:349-353.

6. Fonti R, Del Vecchio S, Zannetti A, De Renzo A, Di Gennaro F, Catalano L, Califano C, Pace L, Rotoli B, Salvatore M: Bone marrow uptake of $99 \mathrm{mTc}$-MIBI in patients with multiple myeloma. Eur J Nucl Med 200I, 28:2।4-220.

7. Munshi NC, Tricot G, Barlogie B: Plasma cell neoplasms. In: Cancer: Principles and Practice in Oncology 6th edition. Edited by: De Vita VT, Hellmann S, Rosenberg SA. PA: Lippincott-Raven; 200I:2465-2499.

8. Beck WT, Grogan TM, Willman CL, Cordon-Cardo C, Parham DM, Kuttesch JF, Andreeff M, Bates SE, Berard CW, Boyett JM, Brophy NA, Broxterman HJ, Chan HS, Dalton WS, Dietel M, Fojo AT, Gascoyne RD, Head D, Houghton PJ, Srivastava DK, Lehnert M, Leith CP, Paietta E, Pavelic ZP, Weinstein R: Methods to detect P-glcyoprotein-associated multidrug resistance in patients' tumors: consensus recommendations. Cancer Res 1996, 56:3010-3020.

9. Moulopoulos LA, Dimopoulos MA: Magnetic resonance imaging of the bone marrow in hematologic malignancies. Blood 1997:2 I27-2| 47.

10. Wakasugi S, Noguti A, Katuda T, Hashizume T, Hasegawa Y: Potential of $99 \mathrm{mT}$ T-MIBI for Detecting Bone Marrow Metastases. J Nucl Med 2002, 43:596-602.

\section{Pre-publication history}

The pre-publication history for this paper can be accessed here:

http://www.biomedcentral.com/1471-2385/3/2/prepub

Publish with Bio Med Central and every scientist can read your work free of charge

"BioMed Central will be the most significant development for disseminating the results of biomedical research in our lifetime. "

Sir Paul Nurse, Cancer Research UK

Your research papers will be:

- available free of charge to the entire biomedical community

- peer reviewed and published immediately upon acceptance

- cited in PubMed and archived on PubMed Central

- yours - you keep the copyright

Submit your manuscript here:

http://www.biomedcentral.com/info/publishing_adv.asp
BioMedcentral 